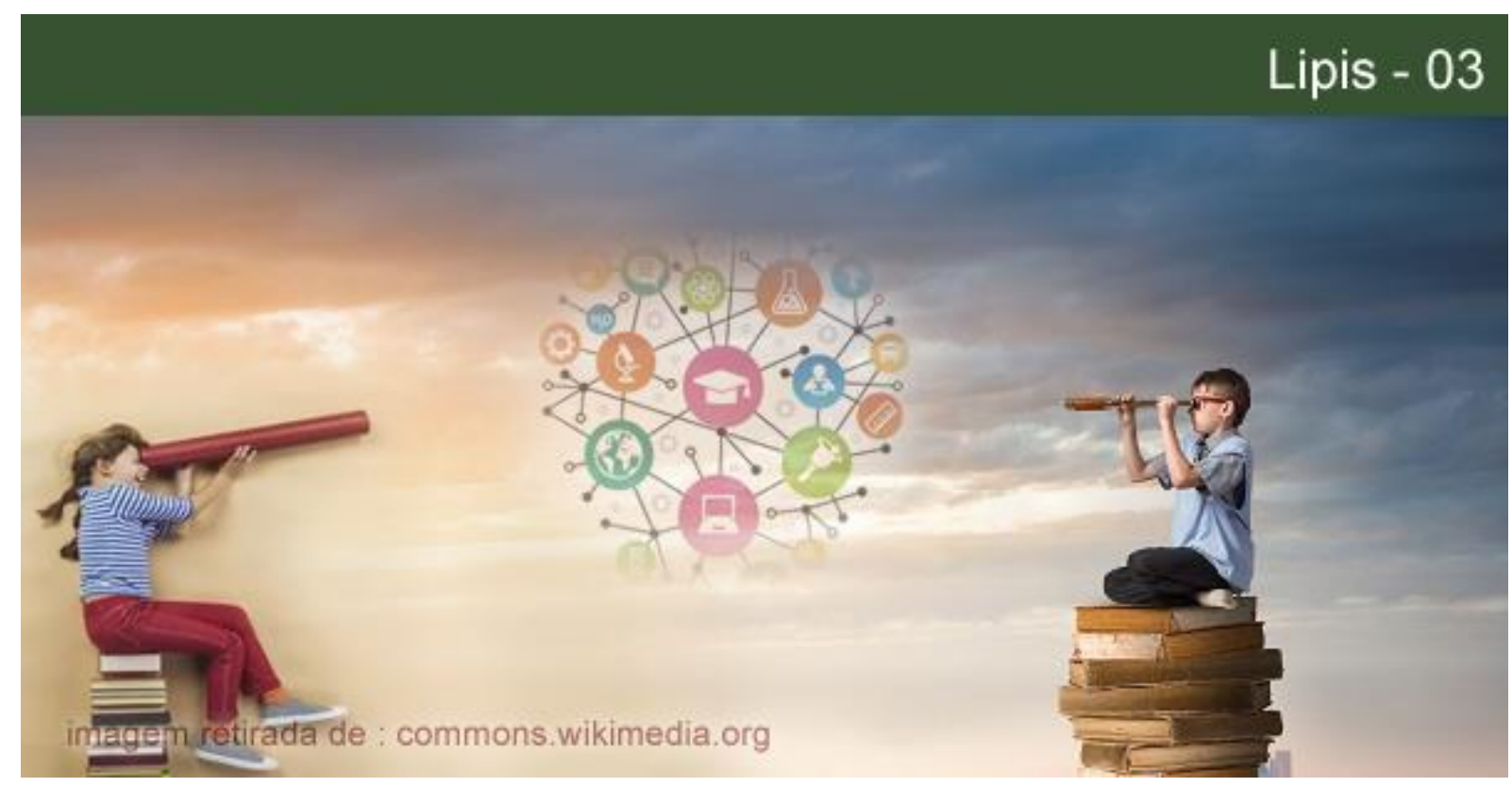

\title{
UM EXERCÍCIO DE RESISTÊNCIA A PARTIR DE PRÁTICAS AUTOGESTIONÁRIAS NA EDUCAÇÃO PÚBLICA DO ESTADO DO RIO DE JANEIRO
}

\author{
Gian Cabral De Lima \\ Doutorado em andamento em Psicologia (Psicologia Clínica) pela Pontifícia Universidade Católica do Rio de \\ Janeiro. Possui mestrado em Psicologia (Psicologia Clínica) pela Pontifícia Universidade Católica do Rio de \\ Janeiro (2016). Participou do programa de intercâmbio oferecido pela Universidade Federal Fluminense - AAI, \\ na Université Paris VIII Saint Dennis, durante o período de um semestre letivo. E-mail: giancabral@gmail.com.
}

\section{Maria Helena Zamora}

Doutora em Psicologia Clínica pela Pontifícia Universidade Católica (PUC-Rio). Professora da PUCRio. Vicecoordenadora do Laboratório Interdisciplinar de Pesquisa e Intervenção Social (LIPIS), da PUCRio. Professora convidada da National/Global Advisory Board for Faith and Justice in Community and Society, com sedeem Indiana, EUA, em 2011. Colaboradora do Instituto de Psicologia Cognitiva, Desenvolvimento Vocacional e Social, da Univ.de Coimbra. E-mail: zamoramh@gmail.com.

Resumo: O presente trabalho consiste no relato de uma experiência de campo ocorrida em uma escola estadual no município de Niterói. A discussão procura se pautar nas diretrizes da pesquisa interversão e da análise institucional para habitar o espaço existencial em questão com o objetivo de analisar as práticas educacionais exercidas neste campo. O método utilizado foi a cartografia de Gilles Deleuze e Felix Guattari. Foi analisada nesta instituição a possível emergência de um grupo sujeito e suas decorrentes práticas de liberdade exercidas através de um dispositivo criado pelos próprios participantes da pesquisa, um projeto pedagógico que visa uma educação libertadora e autogestionária. Todo o processo é pensado dentro do contexto socioeconômico brasileiro e fluminense, para, por fim, se dar a análise do que foi relatado.

Palavras-chave: Experiência. Pedagogia. Escola.

\section{POLÊM!CA $\mid$ LABORE}

Polêmica - Revista Eletrônica da Uerj - Rua São Francisco Xavier, 524, $1^{\circ}$ andar bloco D, sl.1001 • Tels.: +55 21 2334-4088 / 4087 • http://www.e-publicacoes.uerj.br/index.php/polemica/index http://www.labore.uerj.br • laboreuerj@yahoo.com.br 


\title{
AN EXERCISE OF RESISTANCE BASED ON SELF-MANAGED PRATICES IN THE PUBLIC EDUCATION OF THE STATE OF RIO DE JANEIRO
}

\begin{abstract}
The present work consists on the report of a field experience that occurred in a state school in the city of Niterói. The discussion tries to be guided by the guidelines of the interversion research and the institutional analysis to inhabit the existential space in question with the objective of analyzing the educational practices practiced in this field. The method used was the cartography of Gilles Deleuze and Felix Guattari. It was analyzed in this institution the possible emergence of a subject group and its resulting practices of freedom exercised through a device created by the participants of the research, a pedagogical project that aims at a liberating education and self-management. The whole process is thought within the Brazilian and Rio de Janeiro socioeconomic context, in order, finally, to give the analysis of what was reported.
\end{abstract}

Keywords: Experience. Pedagogy. School.

\section{Introdução}

Este artigo consiste no relato de uma pesquisa de campo que teve como território uma escola de ensino médio, que aqui será nomeado de "Colégio Estadual", entre os anos de 2014 e 2015. O trabalho se vale da observação participante, aproximando-se, portanto, das pesquisas etnográficas que mantém um contato direto com os sujeitos e o seu território existencial. O que se apresenta nesta proposta, enquanto diferença, é o esforço de passar da observação participante para a participação observante, afirmando, assim, o seu caráter de intervenção.

O trabalho tem inspiração nas diretrizes do método da cartografia, pensada por Deleuze e Guattari, bem como na Análise Institucional de Lourau e Baremblitt. A partir destes autores é pensado o campo, o saber, a pesquisa e o pesquisador com suas implicações, objetivos e interesses.

Para cartografar um campo, assim como indica Caiafa (2007), o afastamento reside não em relação ao suposto objeto de pesquisa, mas em procurar manter certo grau de afastamento daquilo que o pesquisador considera familiar no território para desta forma experimentar o estranhamento. Pelo fato da instituição escolar estar naturalizada e seus atravessamentos perpassam as relações do cotidiano, isto se torna uma tarefa desafiadora. Portanto, é preciso um esforço maior para chegar ao estranhamento e, assim, questionar determinadas práticas que se cristalizaram ao longo da história da instituição.

Ao entrar em campo, os processos que pretendíamos acompanhar já se encontravam em curso. Começamos pelo meio, entre pulsações (BARROS; KASTRUP, 2009). Além disso, outro grande desafio enfrentado foi o de afirmar este mesmo caráter processual em todos os seus momentos, seja na coleta, na análise, na discussão dos dados ou, principalmente, na escrita dos textos, diários e relatos.

\section{POLÊM!CA $\mid$ LABORE}

Polêmica - Revista Eletrônica da Uerj - Rua São Francisco Xavier, 524, $1^{\circ}$ andar bloco D, sl.1001 • Tels.: +55 21 2334-4088 / 4087 • http://www.e-publicacoes.uerj.br/index.php/polemica/index http://www.labore.uerj.br • laboreuerj@yahoo.com.br 
Ao escrever, há a intenção de transformar o que foi registrado no diário de campo em conhecimento e em modos de fazer, sempre mantendo a preocupação de não passar da descrição para a normatização do campo observado. Para tanto, relatos regulares das visitas e atividades foram registrados, tanto para o que era observado quanto para impressões advindas dos encontros. Além disso, a observação consistia em captar aquilo que se passava no plano intensivo, tomado por forças e afetos. O diário, longe de ser algo próximo a uma ata, era na verdade um relato de experiência ocorrida em determinado momento e local. Deste modo, o material foi de suma importância para a elaboração dos resultados desta pesquisa e da escrita do texto do presente artigo.

O que é afirmado é a importância de que a política de escrita seja condizente com a política de pesquisa e de produção e análise de dados. Como apontam Barros e Kastrup (2009), a questão metodológica fundamental é desenvolver uma política de construção coletiva de conhecimento e não fazer dos participantes meros objetos de pesquisa nos moldes cartesianos. Portanto, é preciso incluir nos relatos as contradições, os conflitos, os enigmas e problemas que estejam em aberto. Ao escrever o relato, a pretensão é mostrar expressões, paisagens e sensações, além do coletivo que se faz presente, não sendo estritamente necessário que as conclusões se configurem como um todo fechado e homogêneo, ou que estas confirmem modelos teóricos já existentes.

Se cartografar é acompanhar processos (BARROS; KASTRUP, 2009), é válido que procuremos sempre indicar que a processualidade esteja presente em todos os momentos. $\mathrm{O}$ processo está nos avanços, nas paradas, ou até mesmo quando acreditamos que, supostamente, houve um retrocesso nas questões do campo, na escrita, na pesquisa. Todos estamos em processo, em construção contínua. No caso específico desta pesquisa, o conhecimento foi produzido coletivamente, em um coletivo se fez com a pesquisa e a pesquisa se fez com o coletivo, em uma coprodução.

Assim, como afirma Rocha (2006), ao entrar em campo, a aposta é na construção do conhecimento entre o saber já elaborado e o fazer que produz continuamente saber, organizando a ação investigada. Para o trabalho pautado na Análise Institucional, é importante a construção de um campo de análise e a organização de conhecimentos históricos, políticos e contextuais sobre o campo de intervenção, no qual buscamos desenvolver o processo de investigação.

\section{POLÊM!CA | LABORE}

Polêmica - Revista Eletrônica da Uerj - Rua São Francisco Xavier, $524,1^{\circ}$ andar bloco D, sl.1001 • Tels.: +55 21 2334-4088 / 4087 • http://www.e-publicacoes.uerj.br/index.php/polemica/index http://www.labore.uerj.br • laboreuerj@yahoo.com.br 
O campo de intervenção só se constitui enquanto tal quando as experiências locais entram em análise à luz da contextualização sócio-histórico-política. Ou seja, quando os efeitos e suas práticas são tomados em toda a sua complexidade, desconstruindo psicologismos, individualizações, determinismos; e o que surge, enfim, é uma análise dos modos de existência daquele território específico.

\section{$O$ relato e a busca contínua das intensidades}

No curso da investigação, começamos pensando a análise da demanda (BAREMBLITT, 1996), criada quando o pesquisador (no caso, psicólogo) oferece seus serviços, podendo esta se modificar ou não, mediante o andamento da pesquisa. O que já indica também o início da análise de implicações ou a análise do sistema de lugares da pesquisa. A demanda veio, especificamente, de um dos professores e da coordenadora pedagógica do Colégio em questão através de um e-mail. Estes solicitavam um apoio para pensar um projeto pedagógico que estava sendo criado pelos próprios professores.

A partir do relato inicial da professora, seria possível traçar a análise daquela demanda. Antes de mais nada é preciso pensar em uma autoanálise: era preciso examinar como a demanda tinha sido criada para, então, chegar à pesquisa. Como nos indica Baremblitt (1996), por trás de toda oferta de um serviço, existe alguém que diz ter algo que falta ao outro, o que acaba gerando uma demanda. Portanto, é necessário articular essa demanda com a oferta.

Primeiramente, a demanda é direcionada ao grupo de pesquisa a que pertencemos e que realiza um trabalho relacionado à educação. O pedido veio de maneira ampla: [para fazer] "um trabalho" - sem queixas ou solicitações específicas. O que restava, então, era realizar o contato com a escola e ouvir o que tinham a dizer. Não levou muito tempo para receber retorno, "claro que interessa!". Sem muita demora fomos convidados a conhecer a escola, conversar com a coordenadora pedagógica e participar de uma reunião com os professores do projeto para discutir estratégias e avaliar as perspectivas para o ano vindouro e realizar um balanço do ano anterior, pois à esta altura nos encontrávamos no fim do ano letivo.

\section{O Colégio Estadual}

O Colégio Estadual está localizado em um município da região metropolitana do Grande Rio. O bairro onde se encontra é majoritariamente residencial e conta com grande parte da sua

\section{POLÊM!CA $\mid$ LABORE}

Polêmica - Revista Eletrônica da Uerj - Rua São Francisco Xavier, $524,1^{\circ}$ andar 
área banhada pelo mar por um lado, e, por outro, um vasto trecho de mata atlântica. A praia em forma de enseada oferece porto seguro para muitos barcos da região, o que faz com que muitos do bairro sejam envolvidos direta ou indiretamente com atividades marítimas.

Segundo relatos, a escola foi inaugurada em um prédio precário, onde a professora que hoje a nomeia foi indicada diretora. Com a ajuda da comunidade e de um patrono que vivia naquela região, foi fundado o antigo curso do ginásio. Novos prédios foram construídos ao redor da casa, também reformada e seu espaço construído foi aumentando. Hoje, ela conta com 22 funcionários (9 “terceirizados”), 100 professores e 788 alunos.

O estabelecimento físico que abriga a escola é formado por três prédios, sendo um mais antigo, que data da inauguração da escola, e outros dois que foram sendo construídos com o passar do tempo, na medida em que a escola foi crescendo. Juntos, os dois têm um formato em "U" e, em seu centro, se encontra uma quadra de esportes, além de um pequeno pátio com árvores. Ambos os prédios se encontram bem conservados. Ao entrar na escola, chamou a atenção a grande quantidade de grades, telas e portas cerradas. Nos painéis na entrada e no corredor, informações, notas e frases motivacionais. Logo fomos para a sala dos professores, para aguardar que a reunião começasse.

É importante, neste momento, destacarmos como a Análise Institucional constrói seu conceito de instituição para darmos seguimento ao relato. Segundo Lapassade (1989), as instituições são formas, são produtos de uma construção histórica e social que se instrumentalizam em estabelecimentos ou dispositivos. A dinâmica de constituição das instituições consiste em um jogo dialético perpétuo entre o instituído (formas) e o instituinte (processos), que resultam em processos de institucionalização, que somos chamados a analisar. O que esse conceito nos traz de potente é a diferença que ele marca entre instituição e estabelecimento ou organização. Pois, não limita a análise, por exemplo, às condições materiais de um estabelecimento ou ao fluxograma de uma organização, mas nos permite de fato analisar a instituição educação, sobretudo em sua dimensão instituinte.

\section{O projeto Núcleo de Aprendizagem Colaborativa em análise}

Um pouco antes da primeira visita, recebemos um arquivo no formato PDF que explicava brevemente a proposta de projeto criada pelos professores. O projeto em questão se tornou parte central da demanda da instituição. No ano de 2013, o Projeto Núcleo de

\section{POLÊM!CA | LABORE}

Polêmica - Revista Eletrônica da Uerj - Rua São Francisco Xavier, $524,1^{\circ}$ andar 
Aprendizagem Colaborativa (NAC) começou a tomar forma. As diretrizes principais que o orientam são autonomia, solidariedade, responsabilidade, honestidade, respeito e a produção de uma postura crítica, que contribua para formação de alunos agentes de transformações.

O projeto NAC se iniciou com cinco turmas do sexto ano, em fase piloto. Sua proposta consistia na implementação de uma nova metodologia pedagógica sintonizada com os desafios contemporâneos. A parte essencial consistia em trazer o aluno para o centro do processo de aprendizagem e torna-lo protagonista na construção do saber. Melhor dizendo, retirar alunos e professores do seu isolamento e fortalecer as práticas de ensino voltadas para o coletivo.

Os idealizadores do projeto afirmam que os objetivos do projeto NAC se encontram em consonância com as políticas públicas contidas na Lei de Diretrizes e Base da Educação Nacional (LDB), que apoia a liberdade de aprendizagem, de ensino, de pesquisa, de divulgação da cultura, do pensamento, da arte e do saber, além do pluralismo de ideias e de concepções pedagógicas. Assegurar essa consonância é fortalecer uma gestão democrática do ensino público, da experiência extraescolar e a vinculação entre a educação escolar, o trabalho pedagógico e as práticas sociais.

O desafio dessa proposta se iniciou a partir da criação de um modelo pedagógico apto a convergir com os saberes locais dos estudantes, apontando sempre para o fomento da iniciativa e da autonomia nestes. Essa metodologia consiste na realização de tarefas a partir de estudos dirigidos que contêm as matérias do currículo mínimo bimestral. Para isso, os alunos se organizam, preferencialmente, em grupos de cinco, e todo o conteúdo do bimestre é gerido através de um planejamento cotidiano. As aulas expositivas, que se concentram no saber do professor e na sua transmissão, são diminuídas e substituídas pelo fomento da iniciativa do aluno em elaborar, de acordo com seu tempo e manejo, o próprio aprendizado.

Para auxiliar a organização dos estudos dirigidos, cartazes foram criados para que os alunos pudessem indicar sua posição no andamento dos estudos, seu nível de entendimento em relação ao conteúdo, suas avaliações em relação aos acontecimentos cotidianos e grupos de organização das tarefas diárias. Tais cartazes funcionam como dispositivos de auxílio e organização da aprendizagem, parte do Planejamento Diário Escolar. Outros dispositivos foram criados, como o cartaz chamado "direitos e deveres", em que os próprios jovens estabelecem, em conjunto, as regras de convivência e avaliam o seu cumprimento, o que acarreta um aumento no grau da autogestão no âmbito escolar.

\section{POLÊM!CA | LABORE}

Polêmica - Revista Eletrônica da Uerj - Rua São Francisco Xavier, 524, $1^{\circ}$ andar bloco D, sl.1001 • Tels.: +55 21 2334-4088 / 4087 • http://www.e-publicacoes.uerj.br/index.php/polemica/index http://www.labore.uerj.br • laboreuerj@yahoo.com.br 
Nessa nova composição, o professor ocupa um lugar diferenciado, onde é denominado de tutor. Ele se torna responsável, em média, por grupos de doze alunos, de acordo com o número de jovens matriculados. A finalidade da criação desses grupos iniciais é, em um futuro breve, alcançar a supressão das salas de aula em toda a escola, que segregam os alunos por séries ou anos letivos, e substituí-las por espaços amplos, permitindo o trabalho coletivo de alunos e professores.

O tutor, neste contexto específico, assume o papel de mediador ou orientador, incentivando a ampliação dos conhecimentos para além do território escolar, deixando, aos poucos, o lugar de detentor exclusivo de um suposto saber transmissível de forma direta e objetiva. O tutor tem como função principal fomentar um espaço de experimentação e reflexão. Esse papel se sustenta, hoje, com o auxílio de uma reunião semanal, durante o tempo de aula, em que é discutido e avaliado o comprometimento e responsabilidade do aluno, através dos planos semanais e do dispositivo "direitos e deveres", além do acompanhamento cotidiano.

A nova concepção de educador leva a apresentar as mudanças efetuadas na avaliação que se torna autoavaliação. Ela ocorre ao longo de todo o processo de aprendizagem, e não somente em períodos específicos, deixando, assim, de ser cumulativa para tornar-se processual. Em síntese, essa proposta visa avaliar a trajetória do aluno durante o período de planejamento semanal e através das atividades dos estudos dirigidos.

Frisamos que os princípios do projeto seguem as orientações da Escola Nova, uma pedagogia que propõe mudanças profundas na instituição escolar. Como nos aponta Almeida (2010), muda a disposição dos alunos em sala de aula, a organização em fileiras paralelas para carteiras soltas e móveis; a forma como o conteúdo é exposto, passa de aulas estritamente expositivas para incluir outros tipos de atividades em grupo (seminários); e a escolha dos tópicos a serem ensinados, feita com a participação dos alunos.

Aliada à proposta da Escola Nova e carregando consigo as mesmas preocupações (preparar o estudante para o mercado de trabalho e exercício da cidadania) a pedagogia de projetos pode ser vista como a versão educacional contemporânea desta antiga proposta. A abordagem pedagógica, criada por Hernández, propõe a reorganização do currículo escolar por projetos e não por disciplinas. Segundo Portes (2005), a pedagogia de projetos tem como objetivo, bem como a Escola Nova, ressignificar o espaço escolar, transformando-o em um espaço aberto ao "real".

\section{POLÊM!CA $\mid$ LABORE}

Polêmica - Revista Eletrônica da Uerj - Rua São Francisco Xavier, $524,1^{\circ}$ andar bloco D, sl.1001 • Tels.: +55 21 2334-4088 / 4087 • http://www.e-publicacoes.uerj.br/index.php/polemica/index http://www.labore.uerj.br • laboreuerj@yahoo.com.br 
O caráter transversal dessa iniciativa se destaca. Como propõe Guattari (2004), em seu conceito de transversalidade, ocorre uma abertura da instituição para outros sentidos e no aumento de quanta comunicacional, tanto intragrupos quanto intergrupos. Ou quando há uma superação da hierarquia vertical e no corporativismo horizontal, trazendo outras formas de relação entre os grupos. Dispositivos são criados para facilitar a circulação dos discursos e dos corpos, abrindo a realidade da instituição para novos encontros e conexões.

\section{Da observação participante à participação observante}

Segundo Passos e Eirado (2009), a dissolução do ponto de vista do observador significa que este desnaturaliza a realidade de determinado objeto, permitindo uma abertura para os diversos pontos de vista que habitam a mesma experiência do real. $O$ pesquisador não se deixa capturar por pontos de vistas dicotômicos, tomando uns como verdadeiros e outros como falsos. A dissolução não significa o abandono da observação, mas sim assumir um olhar em que não há separação entre o objetivo e o subjetivo. O que está em jogo é a contemplação da coemergência do sujeito e do mundo.

Não afirmamos uma política cognitiva que potencializa o distanciamento daquele que conhece e aquilo que deve ser conhecido. Para afirmar a dissolução da observação "distante", ressaltamos o conceito de transversalidade de Guattari (1981), que expressa uma dimensão da realidade que não está restrita a uma identidade, uma individualidade, uma forma, mas experimenta o cruzamento de várias forças que vão se produzindo a partir do encontro entre os diferentes e entre as diferentes junções de uma rede de enunciação, da qual surge um mundo compartilhado. Para Guattari (2004), existem graus de abertura comunicacional ou quantas de transversalidade, que indicam uma variação de um espectro que vai do ponto de vista do proprietário, ou seja, um baixo grau de abertura, passando por pontos de vista não proprietários, em que há um aumento de abertura e referência no coletivo, até a chegada à experiência sem ponto de vista, ou uma experiência que encarna as flutuações do campo comunicacional. A transversalidade é mais uma direção de variabilidade desses pontos de vista do que a eliminação dos mesmos ou sua variabilidade do que uma experiência sem ponto de vista, quase uma utopia (PASSOS; EIRADO, 2009). Trata-se de ser perpassado pelas múltiplas vozes que atravessam um processo, sem apoiar-se em nenhuma como determinante. O conceito de transversalidade

\section{POLÊM!CA | LABORE}

Polêmica - Revista Eletrônica da Uerj - Rua São Francisco Xavier, 524, $1^{\circ}$ andar bloco D, sl.1001 • Tels.: +55 21 2334-4088 / 4087 • http://www.e-publicacoes.uerj.br/index.php/polemica/index http://www.labore.uerj.br • laboreuerj@yahoo.com.br 
indica uma direção para o trabalho realizado no campo, tanto metodológica quanto de intervenção.

Posto desta forma, várias questões se impuseram, como o tempo de trabalho curto, a enorme distância percorrida e os custos. Apesar dos percalços, estávamos implicados com o trabalho com uma escola pública, afirmando, assim, um ensino público, gratuito e de qualidade. Em todas as visitas procuramos sempre manter a atenção concentrada, como indica Kastrup (2002), porém sem focalização, uma atenção à espreita.

Ouvimos os desafios, conquistas, dúvidas e anseios, todos falaram um pouco de suas expectativas e limitações em relação ao NAC. A maioria dos presentes parecia bastante engajada em suas atividades. Várias questões vieram à tona nos encontros em que participamos, como problemas econômicos, políticas públicas insuficientes, falta de recursos, como trabalhar satisfatoriamente utilizando o novo método, falta de professores, funcionários e colaboradores. Porém, apesar de tudo isso, todos pareciam dispostos a avançar com o projeto.

O projeto teve início em conversas de corredor e posteriormente em reuniões de grupo de estudos, pesquisaram possibilidades de acordo com a estrutura da escola e sua capacidade. Após um semestre de estudos e discussões, o coletivo começou a implementar algumas das propostas. Nenhum dos profissionais é compelido a aplicar as modificações, todos têm total liberdade de trabalho nas suas salas de aula e ninguém participa do projeto, ou dos encontros, por coerção de nenhuma natureza, afirmando mais uma vez seu caráter transversal. Nesse mesmo dia, estabelecemos um acordo inicial que afirmava nossas visitas todas as terças, durante as reuniões do projeto, pois o ano letivo tinha terminado e não contávamos com a presença dos alunos na escola.

As reuniões eram noturnas, o que tornava tudo complicado pelas distâncias e trânsito envolvidos. Porém, seguimos frequentando as reuniões, que consistiam na tentativa de atrair parceiros que pudessem contribuir de alguma forma para o projeto.

Diversos profissionais das mais variadas áreas compareciam às reuniões ofertando as suas contribuições, que seriam avaliadas e discutidas pelos professores, função que eu acreditei ser um pouco esperada de nós também, embora não nos tenham colocado especificamente neste lugar, que foi avaliado como o lugar de alguém que fornece um serviço de consultoria, o que não era o caso. Também eram comuns muitas queixas de diferentes níveis e de diferentes

\section{POLÊM!CA | LABORE}

Polêmica - Revista Eletrônica da Uerj - Rua São Francisco Xavier, 524, $1^{\circ}$ andar bloco D, sl.1001 • Tels.: +55 21 2334-4088 / 4087 • http://www.e-publicacoes.uerj.br/index.php/polemica/index http://www.labore.uerj.br • laboreuerj@yahoo.com.br 
profissionais. Os pressupostos do projeto foram debatidos algumas vezes e a discussão girava em torno principalmente do rigor, ou a falta dele, quando o método era utilizado.

Por algumas vezes os professores discutiram sobre o quanto deixar que os alunos tenham um determinado nível de autonomia e responsabilidade pode incorrer na inércia por parte destes. Para solucionar tal problema, estratégias individuais foram traçadas, dependendo de cada matéria, de cada professor e de cada situação específica, indicando uma grande abertura tanto no nível comunicacional quanto no nível das práticas.

Em um determinado momento, as reuniões terminaram, pois o ano letivo ia começar. Os professores entraram de férias e precisavam se dedicar aos preparativos do próximo ano. A estratégia traçada para o trabalho consistia em visitas à escola em horários como entrada, recreio, saída e intervalos entre as aulas. Acompanhamos a rotina da escola e, o mais importante, assistimos a algumas aulas. Todas as visitas eram um desafio. Primeiramente, porque era nossa primeira pesquisa de campo. Entretanto, seguimos as pistas da cartografia, que afirmam que o papel do pesquisador não é abarcar todo o campo, mas acompanhar os processos e traçar seu mapa de constituição.

Enquanto visitávamos a escola, foi solicitado pessoalmente a cada professor, participante ou não do projeto, nossa participação em alguma das suas aulas, em que eles tinham toda a liberdade de escolher a turma em que eles gostariam que as suas aulas fossem assistidas e, obviamente, também tinham a opção de negar, porém não nos foi negado acesso em momento nenhum. Durante as visitas, todos nos receberam muito bem e foi possível, além de observar o seu cotidiano e as suas práticas, conversar com cada um deles, saber um pouco como era o seu dia a dia, como também as suas angústias, os seus desafios, as suas perspectivas e projeções. Por fim, enquanto fazia as visitas, convidava os professores a participarem de entrevistas individuais para a complementação da pesquisa.

Os professores foram escolhidos para colaborarem com a pesquisa pela sua participação nas reuniões do projeto e os que não participavam do mesmo foram indicados pela professora orientadora da escola.

\section{A sala de aula e a intensificação da experiência}

Passamos, agora, a relatar alguns dos acontecimentos ocorridos nas visitas às salas de aula, o momento em que a pesquisa se intensificou, pois é nela que todos passam a maior parte

\section{POLÊM!CA | LABORE}

Polêmica - Revista Eletrônica da Uerj - Rua São Francisco Xavier, $524,1^{\circ}$ andar bloco D, sl.1001 • Tels.: +55 21 2334-4088/4087 • http://www.e-publicacoes.uerj.br/index.php/polemica/index http://www.labore.uerj.br • laboreuerj@yahoo.com.br 
do tempo e onde realmente é possível experimentar a escola e sua vivacidade. Então, quando começamos a frequentar as aulas, para nós, foi como se voltássemos aos tempos de aluno do ensino médio, pelas lembranças e afetos que nos ocorreram. A presença dos alunos muda de maneira drástica a visão da escola pela maneira como eles a ocupam. Entrar e sair pelos corredores da escola é ter a impressão de deslizar de trem sobre seus trilhos, e sentir a variabilidade do murmúrio dos alunos dá a impressão de estar dentro de uma grande máquina em funcionamento. Quando ocupada plenamente, até o cheiro da escola muda, a sua atmosfera passa a ser mais densa e calorosa. Alguns poucos alunos nos conheciam de vista. Sempre que entravámos em sala, fazíamos uma apresentação e explicávamos o porquê de estarmos ali, explicávamos o que iriámos fazer e também o que não iriámos fazer. Por fim, nos oferecíamos aos seus questionamentos. Porém, perguntas nunca foram feitas.

Durante o tempo em que habitei esse território, fui calorosamente recebido pelos estudantes. Fomos convidados a jogar futebol e basquete, todos conversavam de maneira muito amistosa e, volta e meia, curiosa. Os alunos pareceram muito curiosos, mas não em relação à pesquisa, e sim em relação à cultura pop. Fomos indagados algumas vezes sobre filmes, livros e séries internacionais em voga. Era possível perceber também onde se concentravam, durante o recreio e os intervalos, que seria sempre ou ao lado da sala dos professores, devido ao uso da rede de internet da escola através do sistema de internet sem fio, ou na quadra e espaços abertos, onde praticavam esportes coletivos ou simplesmente conversavam. Porém a biblioteca da escola, que foi elogiada por muitos professores, permanecia inabitada, apesar de sempre aberta.

Nossa visão dos alunos contrastava com os relatos de violência, que variavam de um professor para o outro. Não presenciei nada grave: alguns empurrões, xingamentos e uma briga, que foi rapidamente resolvida. Talvez a presença ostensiva da Polícia Militar por perto coibisse a violência física. Na turma em que mais presenciei casos de violência, em algum momento, ouvimos de um aluno da turma considerada a mais violenta: "Tio, fica tranquilo! Você já é de casa". Então, após sua frase, ele saiu correndo. A frase pairou no ar como um enigma.

Já com relação à participação dos alunos nos processos deliberativos da escola, em uma das aulas, recebemos uma notícia, através de um professor, que os alunos tinham acabado de criar um grêmio estudantil para discutir questões sobre seu cotidiano. O grêmio já tinha sido proposto em um passado recente mas não se firmou. A importância deste formato de organização é grande, pois durante as reuniões, eles serão capazes de ampliar sua participação;

\section{POLÊM!CA | LABORE}

Polêmica - Revista Eletrônica da Uerj - Rua São Francisco Xavier, 524, $1^{\circ}$ andar bloco D, sl.1001 • Tels.: +55 21 2334-4088 / 4087 • http://www.e-publicacoes.uerj.br/index.php/polemica/index http://www.labore.uerj.br • laboreuerj@yahoo.com.br 
ou seja, esse dispositivo pode vir a ser capaz de ampliar e sustentar um espaço de diálogo na escola.

Após dois anos de realização do NAC, que prevê abertura para os projetos idealizados pelos alunos, começaram a surgir propostas de trabalho destes. Até o fim das minhas visitas, três já tinham sido apresentados. Com ajuda da professora de português, os estudantes deveriam apresentá-lo, de acordo com uma estrutura predefinida. Em seguida, a proposta seria encaminhada para apreciação e, se viável, os próprios alunos se organizariam para colocar aquilo que escreveram no projeto em prática com o auxílio de alguns professores.

De volta aos relatos, ao entrar procurávamos ter o cuidado de sentar nas carteiras dos alunos e na fileira perto da parede e não ao lado do professor. Buscávamos ocupar outro lugar enquanto pesquisadores, que não o de detentores de conhecimento transmissível. Talvez o lugar em questão ainda estivesse em formação constante. Sempre que possível, sentávamos entre os alunos e o professor, apenas virando a carteira de lado para não ficar de costas nem para um, nem para o outro.

$\mathrm{Na}$ maioria das aulas, nossa presença interferiu significativamente na rotina. Os estudantes ficavam agitados e os professores tinham trabalho para conter as brincadeiras, conversas, sussurros e digressões; o que, um dia, chegou a gerar até uma reclamação, proveniente do professor, na direção.

Apesar de alguns alunos se encontrarem implicados, ao ponto de eles mesmos criarem um projeto próprio, certo dia, um aluno, já na saída, perguntou: "Você é daquele projeto chato?" Ao que respondo: "Sim, estou aqui para assistir às aulas do projeto. O que você vê de chato nele?". "Ah, é tudo chato! É a gente que tem que ficar fazendo as coisas." Quando solicitamos que ele se aprofunde, o estudante diz não querer falar e pede para ir embora.

O contexto específico dessa declaração foi quando presenciei, nas salas, o término da criação dos "direitos e deveres", que consistiam em quadros com o nome das turmas, os horários e o que os alunos deveriam respeitar, no ambiente escolar. Isso exigiu um grande esforço dos alunos e insistência por parte dos professores. Foi curioso notar que as regras criadas por eles mesmos não eram respeitadas. O conteúdo geral dos quadros era composto por regras gerais, como a proibição do uso do celular, de conversas, evitar saídas frequentes da sala, levantar a mão para falar e outros comportamentos. A base de todo o quadro consistia no respeito mútuo, porém, após sua criação, não pude acompanhar como ele operou no cotidiano.

\section{POLÊM!CA | LABORE}

Polêmica - Revista Eletrônica da Uerj - Rua São Francisco Xavier, $524,1^{\circ}$ andar bloco D, sl.1001 • Tels.: +55 21 2334-4088 / 4087 • http://www.e-publicacoes.uerj.br/index.php/polemica/index http://www.labore.uerj.br • laboreuerj@yahoo.com.br 
O quadro tinha uma estrutura preconcebida, mas todo o resto era criação dos alunos, até mesmo o nome que substituiria o acima citado por algum do gosto deles. Tudo era decidido através de votação, com exceção do quadro de horários das aulas. O motivo de este horário estar contido no quadro era pelo fato de que os alunos constantemente esqueciam o horário da aula de determinado professor e não traziam o material para trabalharem na sua aula.

Em relação ao cotidiano de aulas, foi possível perceber que o nível de adesão ao NAC variava enormemente. Conheci professores que abraçaram o máximo possível a proposta; outros, alguns pressupostos e, finalmente, alguns que a desconsideraram totalmente. Isso variava, em diversas práticas: como os alunos estavam dispostos na sala, como os professores ministravam as aulas, como a as tarefas eram propostas, as avaliações eram feitas, corrigidas e vistoriadas.

No que tange as aulas ministradas, aquelas que têm mais influência do projeto NAC, os alunos, geralmente, leem aquilo que é escrito no quadro ou em seus livros e, em seguida, o tema é exercitado, usando questões amplas, que incentivem a interpretação criativa, ou consultas em outras fontes, como mapas, por exemplo. Tudo é respondido sempre coletivamente, o que torna a atividade bem interessante. O que foi observado, durante algumas aulas, é que os alunos leem bem e interpretam bem suas leituras, fazendo com que algumas aulas sejam bem dinâmicas.

Se os professores aderem mais à maneira de ensinar tradicional, suas avaliações são feitas através de provas; se resolvem aderir às diretrizes do projeto, os alunos são avaliados através de sua produção cotidiana. Dito isso, para fazer entender que o Colégio não trabalha com um padrão específico de procedimentos que é imposto ao professor e eles têm liberdade de inventar novas maneiras de ensinar, inclusive criam a sua própria.

Os alunos mantêm diversas oficinas em funcionamento e outras mais pontuais. Dentre as oficinas mais frequentes, temos a oficina de horta, em que eles limpam o terreno, plantam e regam o que já foi plantado; oficina de compostagem, em que eles produzem o adubo; e a reciclagem de materiais diversos.

Por várias vezes, houve queixa de professores e funcionários relacionada ao dinheiro, ou melhor, à falta deste. O dinheiro ou o capital é um grande analisador social, nos dias atuais. Sendo assim, eu me pergunto: verbas e capital abundante, por si só, resolveriam o problema da escola? Como passaria a ser o seu funcionamento, com uma verba digna (nunca saberemos)? $\mathrm{O}$ que pode ser feito, dada a verba, para que o ensino seja o mais satisfatório possível?

\section{POLÊM!CA | LABORE}

Polêmica - Revista Eletrônica da Uerj - Rua São Francisco Xavier, $524,1^{\circ}$ andar bloco D, sl.1001 • Tels.: +55 21 2334-4088/4087 • http://www.e-publicacoes.uerj.br/index.php/polemica/index http://www.labore.uerj.br • laboreuerj@yahoo.com.br 
Não afirmo, com esse questionamento, que seja fácil, desejável ou que devamos nos conformar com condições precárias de trabalho, sobretudo no ambiente escolar, mas procuro tentar acionar as saídas possíveis para tal problema. Essas saídas existem? De certa maneira, a ideia e a consequente implementação do projeto favoreceram, de maneira ampla, o trabalho de uma parcela dos professores, pois os colocava em constante diálogo, tanto entre eles mesmos quanto com pensadores da educação, através de grupos de estudo. A procura constante de parceiros externos para a escola abre suas portas para a comunidade e para a cidade.

Existe, na escola, um desejo de operar de maneira diferenciada. A escassez de recursos não paralisa a escola na mera reclamação, pelo contrário, parece colocá-la em movimento. Trouxe união entre um grupo de professores que queria mais do que queixar-se e esperar uma solução vinda de fora. Muitas adversidades são encontradas, algumas resolvidas e outras ainda por se resolverem e muitas outras por vir.

Em um contexto onde os jovens são pensados pelo poder sempre enquanto um novo nicho de mercado a ser explorado (ou como problemas), a força da educação é constantemente utilizada para comercializar todos os aspectos de suas vidas. Seja através da internet, redes sociais ou das novas tecnologias de mídia, empresas buscam mergulhar os jovens o mais cedo possível no mundo do consumo. A problemática maior do capital consiste no adestramento desses jovens ao mundo pautado em consumir. Já por outro lado, o Estado se exime cada vez mais de educar a população; as escolas acabam flertando com a possibilidade de serem substituídas por academias voltadas para o consumo (BAUMAN, 2012). Em outras palavras, a lógica da educação enquanto produto ou serviço impera em face à lógica da educação enquanto direito e produtora de emancipação.

Frigotto (2011) aponta de maneira semelhante para uma regressão da educação escolar de um direito social para uma mercadoria. Com o advento da noção de capital humano, nos anos 1950, a educação escolar se alia de forma ampla aos interesses do mercado econômico, passa a ser vista como causa de desenvolvimento econômico e salvação perante os estigmas das populações mais pobres do planeta. Porém, para o autor o que está velado nessas concepções, é um sistema social que culpa as vítimas por serem exploradas e pela desigualdade imposta sob estas.

Dado tal contexto, podemos pensar todo esse movimento enquanto resistência ao poder, resistência essa que se dá através de práticas de autogestão, de um movimento que busca criar

\section{POLÊM!CA | LABORE}

Polêmica - Revista Eletrônica da Uerj - Rua São Francisco Xavier, 524, $1^{\circ}$ andar 
novas maneiras de existir e de estarmos juntos. Pois, tendo a ideia de poder como relação de forças (FOUCAULT, 1969), produzindo afetos, tendo a capacidade de afetar e de ser afetada, a resistência aparece enquanto um terceiro elemento da força. Sendo esta a capacidade da força de se colocar fora dos cálculos do poder sendo, portanto, o oposto de reagir, pois reagindo fazemos exatamente aquilo que o este espera de nós. Já resistindo criamos formas de existir dentro de composições de força que não estavam dadas. Portanto, resistir é criar a partir das forças do devir, de mutação, criando novas possibilidades de vida.

$\mathrm{O}$ que se engendra nesta experimentação e nesta forma de resistir é uma postura autogestionária. Porém, como nos indica Guattari (1968), não existe uma "filosofia geral" da autogestão que possamos aplicar em qualquer situação. Quando tal, estamos incorrendo no risco de nos tornamos reformistas, de trazermos mais uma vez soluções prontas e verticalizadas a questões locais e pontuais, como são tão conhecidas em nossa história da educação no Brasil. É preciso sempre discutir os alcances e os limites da autogestão. Mesmo que pensemos um determinado tipo de pedagogia voltada para processos libertários, seu exercício tem que ser refletido a todo instante.

No grupo, seus integrantes produziam um saber sobre suas próprias questões, condições e experiências. Organizavam-se em grupos de discussão, assembleias e buscavam estar sempre aliados àquilo que almejavam. Através do saber que adquiriam sobre eles próprios, tentavam construir uma realidade diferente, se auto-organizando. Além disso, produzindo o saber sobre as suas condições, eles têm possibilidade de equivocar saberes dominantes.

Nos ocuparemos agora da noção de grupo e como nesta instituição é bem marcada a distinção entre dois tipos de grupos específicos. Sendo assim, como nos indica Guattari (1964), um destes grupos seria o grupo sujeito e o outro o grupo sujeitado. O primeiro grupo se caracteriza por controlar seu comportamento, este grupo é ouvido e ouvinte, fazendo assim emergir as estruturas de hierarquização, permitindo então uma abertura para além dos interesses do próprio grupo. O grupo sujeito enuncia algo, é capaz de criar suas próprias leis e suas condições de constituição, porém sem perder de vista sua condição de finitude. Já o grupo sujeitado tem sua causa ouvida, não se sabendo onde e nem por quem. Está sempre marcado por uma hierarquização e por uma submissão a outros grupos. Baremblitt (2002) afirma este grupo como sendo alienado de suas leis, objetivos e procedimentos.

\section{POLÊM!CA | LABORẸ}

Polêmica - Revista Eletrônica da Uerj - Rua São Francisco Xavier, 524, $1^{\circ}$ andar bloco D, sl.1001 • Tels.: +55 21 2334-4088/4087 • http://www.e-publicacoes.uerj.br/index.php/polemica/index http://www.labore.uerj.br • laboreuerj@yahoo.com.br 
Podemos encarar o grupo do projeto NAC enquanto um coletivo mais alinhado com a ideia de grupo sujeito, tentando, apesar de todas as dificuldades, se colocarem enquanto criadores de suas próprias regras, leis e procedimentos. Não mais se alienar perante o Estado e esperar que dele surja a verba, a lei ou a portaria salvadora se faz urgente para eles.

Neste tortuoso caminho é preciso ter cuidado e estar sempre atento às armadilhas do poder que tende sempre a nos capturar, porém o grupo segue lutando e potente. Uma experiência como esta ultrapassa as categorias de sucesso/fracasso e tem que ser analisada de maneira diferente. Não existe um ponto ideal a ser alcançado ou a plenitude de um processo de autogestão. O que está em jogo são experimentações.

\section{Referências}

ALMEIDA, J. L. V. A Escola Burguesa e a Questão do Conhecimento: mudar para não transformar. Revista Espaço Acadêmico (UEM), v. 9, p. 53-63, 2010.

BAREMBLITT, G. Compêndio de Análise Institucional e outras correntes: teoria e prática. 5. ed. Belo Horizonte: Instituto Félix Guattari, 2002.

BAUMAN, Zygmunt. Sobre educação e juventude: conversas com Riccardo Mazzeo. Rio de Janeiro: Zahar, 2013. $131 \mathrm{p}$.

BARROS, Laura Pozzanade; KASTRUP, V. Cartografar é acompanhar processos. In: KASTRUP, Virgínia; PASSOS, Eduardo; ESCÓSSIA, Liliana da. (Org.). Pistas do Método da Cartografia. Pesquisa - intervenção e produção de subjetividade. 2. ed. Porto Alegre: Editora Sulina, 2009. v. 01, p. 52-75.

CAFAIA, J. Aventura das cidades. Rio de Janeiro: Ed. FGV, 2007.

FOUCAULT, M. L’archéologie Du Savoir. Paris: Gallimard, 1969.

FRIGOTTO, Gaudêncio. Novos fetiches mercantis da pseudoteoria do capital humano no contexto do capitalismo tardio. In: ANDRADE, Juarez de; PAIVA, Lauriana G. de (Orgs.). As políticas públicas para a educação no Brasil contemporâneo. Juiz de Fora: Editora UFJF, 2011. p. 18-35.

GUATTARI, Felix. A transversalidade (1964). In: Psicanálise e Transversalidade: ensaios de análise institucional. São Paulo: Ideias \& Letras, 2004.

Autogestão e Narcisismo (1968). In: institucional. São Paulo: Ideias \& Letras, 2004. Psicanálise e Transversalidade: ensaios de análise

KASTRUP, V. Cartografias Literárias. Revista do Departamento de Psicologia (UFF), Niterói, v. 14, n.2, p. 23-38, 2002.

LAPASSADE, G. Grupos, organizações e instituições. Rio de. Janeiro: Francisco Alves, 1989.

PASSOS, E.; BARROS, R. B. A construção do plano da clínica e o conceito de transdisciplinaridade.

Psicologia. Teoria e Pesquisa, Brasília, v. 16, n.1, p. 71-79, 2000(a).

\section{POLÊM!CA $\mid$ LABORE}

Polêmica - Revista Eletrônica da Uerj - Rua São Francisco Xavier, 524, $1^{\circ}$ andar bloco D, sl.1001 • Tels.: +55 21 2334-4088 / 4087 • http://www.e-publicacoes.uerj.br/index.php/polemica/index http://www.labore.uerj.br • laboreuerj@yahoo.com.br 
PASSOS, E.; EIRADO, A. Cartografia como dissolução do ponto de vista do observador. In: KASTRUP, Virgínia; PASSOS, Eduardo; ESCÓSSIA, Liliana da. (Org.). Pistas do método da cartografia: pesquisaintervenção e produção de subjetividade. Porto Alegre: Sulina, 2009. p. 110-131.

ROCHA, M. L. Psicologia e práticas institucionais: a pesquisa-intervenção em movimento. Psico (PUCRS), v. 37, p. 169-174, 2006.

Recebido em: 01/02/2018.

Aceito em: 02/03/2018.

\section{POLÊM!CA $\mid$ LABORE}

Polêmica - Revista Eletrônica da Uerj - Rua São Francisco Xavier, 524, $1^{\circ}$ andar bloco D, sl.1001 • Tels.: +55 21 2334-4088 / 4087 • http://www.e-publicacoes.uerj.br/index.php/polemica/index http://www.labore.uerj.br • laboreuerj@yahoo.com.br 